\title{
Bond of reinforcing bars in cracked concrete
}

\author{
P. Desnerck, J.M. Lees \& C. Morley \\ Engineering Department, University of Cambridge, Cambridge, UK
}

\begin{abstract}
Cracks are inherent in reinforced concrete structures. The origin of cracks can be manifold. At early stages they can be caused by plastic settlement, shrinkage, drying shrinkage, etc. Typically, the most severe forms of cracking in reinforced concrete structures are those caused by the corrosion of the reinforcing bars. Corrosion products are expansive in nature and tend to generate tensile stresses in the concrete surrounding the corroding bars. As soon as these stresses exceed the tensile capacity of the concrete, cracks around and along the reinforcing bars are formed.

In assessing existing structures engineers often notice severe cracking due to corrosion or longitudinal cracks due to plastic shrinkage e.g. in the anchorage zones. The section loss of these bars can easily be taken into consideration when performing load bearing capacity checks, but questions arise with respect to the remaining bond capacity of the rebars in the cracked concrete.

This study aims to quantify the influence of different parameters on the bond strength of reinforcing bars in cracked concrete. Rather than performing accelerated corrosion tests, it focuses on the effect of cracking itself (in absence of corrosion products) so the results can be used for non-corrosion related cases as well. Parameters under investigation include the confinement, concrete cover, crack direction and crack extension. Results show that single cracks as narrow as $0.03 \mathrm{~mm}$ can have a significant influence on the obtained bond strengths.
\end{abstract}

\section{INTRODUCTION}

Concrete is an inhomogeneous material with a relatively low tensile strength. Therefore it is often used in combination with steel reinforcement so that the steel can resist tensile stresses after cracking. The load bearing capacity of reinforced concrete structures depend highly on the interaction between reinforcing bars and the surrounding concrete (Task Group Bond Models 2000). Over time the bond can degrade due to deterioration of the reinforcement.

Cracks are inherent in reinforced concrete structures and are caused by a number of different types of actions (BRE Centre for Concrete Construction 2000). One of the most severe forms of cracking in reinforced concrete is the result of the corrosion of the reinforcing bars. Due to carbonation and chloride ingress a favourable environment is created for corrosion to initiate and corrosion products to be formed (BRE Centre for Concrete Construction 2000). Fib bulletin No. 10 (Task Group Bond Models 2000) categorises the effects of corrosion into 3 potential consequences:

- loss of reinforcing bar section

- creation of a weak interfacial layer at the reinforcing bar/concrete interface

- volumetric expansion of the reinforcing bar
The last two phenomena have a direct influence on the bond of the reinforcing bar. On one hand, a weak interface layer of brittle corrosion products surrounding the reinforcing bar increases the relative displacement of the bar with respect to the concrete at certain load levels. On the other hand corrosion products are expansive in nature and tend to generate tensile stresses in the surrounding concrete. At low levels this expansion may be advantageous but once these stresses exceed the tensile capacity of the concrete, cracks around and along the reinforcing bars develop (Task Group Bond Models 2000). The reduction in confinement due to these cracks then leads to a progressive reduction in the bond strength. Hence, understanding of the link between corrosion rates, the induced cracking (and crack widths) and the reduction in bond capacity is essential.

To investigate crack formation due to corrosion, researchers (Rodriguez et al. 1994; Andrade et al. 1993; Al-Sulaimani et al. 1990; Clark \& Saifullah 1994; Almusallam et al. 1996; Clark \& Saifullah 1993; Alonso et al. 1998) have undertaken accelerated corrosion tests on reinforced concrete specimens where impressed currents of 0.003 to 10 $\mathrm{mA} / \mathrm{cm}^{2}$ were applied. Table 1 summarizes results found in literature on the corrosion levels to cause cracking of the concrete cover. The corrosion levels are expressed as a percentage of bar cross-sectional area loss (section loss expressed as a uniform metal 
Table 1. Overview of reported corrosion levels to cause concrete cover cracking.

\begin{tabular}{lllll}
\hline Study & $\begin{array}{l}\phi \\
{[\mathrm{mm}]}\end{array}$ & $\begin{array}{l}\text { Cover ratio } \\
{[-]}\end{array}$ & $\begin{array}{l}\text { Section loss } \\
{[\%]}\end{array}$ & $\begin{array}{l}\text { Corrosion } \\
\text { Penetration } \times[\mathrm{mm}]\end{array}$ \\
\hline (Al-Sulaimani et al. 1990) & 10 & 7.50 & 5.00 & 0.130 \\
& 14 & 5.36 & 3.00 & 0.110 \\
& 20 & 3.75 & 2.00 & 0.100 \\
(Clark \& Saifullah 1993) & 8 & $0.50-2.00$ & $0.40-1.30$ & $0.008-0.026$ \\
(Andrade et al. 1993) & 16 & $1.25-1.88$ & $0.40-0.50$ & $0.015-0.020$ \\
(Rodriguez et al. 1994) & 16 & $2.00-4.00$ & $0.40-1.00$ & $0.015-0.040$ \\
(Clark \& Saifullah 1994) & 8 & 1.00 & $0.30-0.55$ & $0.006-0.011$ \\
(Almusallam et al. 1996) & 12 & 5.00 & 4.00 & 0.120 \\
(Alonso et al. 1998) & $8-16$ & $1.25-7.00$ & $0.19-1.30$ & $0.015-0.065$ \\
\hline
\end{tabular}

loss around the circumference of the reinforcing bar) and corrosion penetration depth $\times$ radially into the bar. Although there is some scatter on the obtained values, all studies agree that a relatively low corrosion penetration depth, ranging from 0.008 to $0.130 \mathrm{~mm}$, causes cracking.

Rodriguez et al. (Rodriguez et al. 1994) found that cracks were initiated for corrosion levels associated with bar radius reductions as low as $0.015 \mathrm{~mm}$ to $0.040 \mathrm{~mm}$.

One issue with accelerated corrosion bond tests is that they study the combined effect of cracking and the formation of a soft layer of corrosion products around the reinforcement. While these effects co-exist in practice, it leads to difficulties in analysing the processes at a fundamental level. Furthermore the results cannot be applied to situations in which cracks are present in the absence of corrosion (e.g. plastic shrinkage cracks in congested reinforcement lay-outs).

Therefore this study aims to quantify the bond strength of reinforcing bars in cracked concrete. Rather than performing accelerated corrosion tests, it focuses on the more fundamental effect of the cracking itself (in absence of corrosion products). To achieve this aim, a novel test method is developed.

\section{CRACK GENERATION}

When assessing existing structures, engineers often observe severe cracking due to corrosion. Some common corrosion induced crack patterns are shown in Figure 1.

As discussed, most studies on the bond properties of cracked concrete specimens have used accelerated corrosion techniques. However, these techniques have the tendency to lead to less controllable crack patterns and a wide range of obtained crack widths.

In this study the principles of a controlled split tensile test is applied to pre-crack specimens. In this way rough crack surfaces are then formed along a predefined cracking plane running through
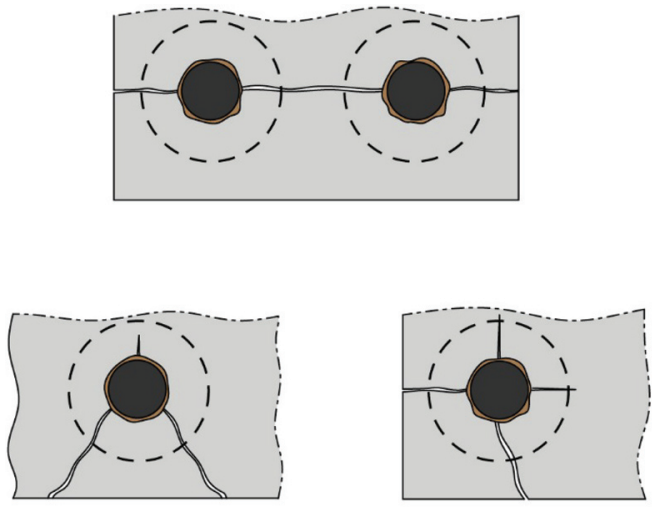

Figure 1. Possible cracks patterns in reinforced concrete due to corrosion.

the axis of the reinforcing bar. To avoid brittle failure and provide some post-cracking confinement, the specimen can be cast within a plastic ring. This ring can remain in place during both the pre-cracking and pull-out phases. With this technique, single or double cracks can be generated to represent observed crack patterns in existing structures.

Of particular interest are the bond reductions during the early stages of corrosion and thus the onset of cracking. The splitting tests seek to achieve 0.03 to $0.04 \mathrm{~mm}$ crack widths. These crack widths are relatively small compared to the allowable crack widths of 0.20 to $0.30 \mathrm{~mm}$ according to reinforced concrete design guidance (European Committee for Standardization 2004).

\section{EXPERIMENTAL PROGRAM}

\subsection{Experimental specimens and overview of test method}

In order to represent common crack patterns (as illustrated in Figure 1) and determine the bond 

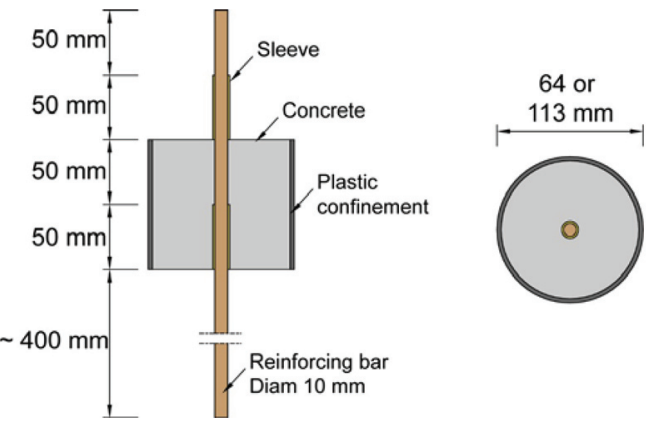

Figure 2. Specimen geometry.

strength of reinforcing bars in cracked, the test method includes one or two pre-cracking phases followed by standard bond strength "pull-out tests" (RILEM TC 1970).

In the pre-cracking phase(s) the specimens are subjected to a split cylinder test. Two line loads are applied on the specimen on opposite sides and along the axis of the concrete cylinder until first cracking of the concrete, at which point the specimen is unloaded. For double cracked specimens, the specimen is rotated 90 degrees after the first pre-cracking experiment and the same procedure is repeated to induce the second crack. Pull-out tests are then conducted on the cracked specimens to determine the influence of the cracks on the bond behaviour.

Cylindrical specimens with a diameter of either $107 \mathrm{~mm}$ or $60 \mathrm{~mm}$, and a height of $100 \mathrm{~mm}$ are used. A reinforcing bar with a diameter of $10 \mathrm{~mm}$ is centrally placed in the specimen, resulting in a cover-to-diameter ratio of 4.8 or 2.5. The specimens are cast with a bond length of 5 times the bar diameter. The bond length itself is reduced by providing a sleeve over the bar in the lower $50 \mathrm{~mm}$ (Figure 2). The specimens are cast in a plastic cylindrical mould which was used as confinement for the specimen during the pre-cracking phases and in many cases also remained in place for the pull-out tests.

\subsection{Main parameters}

Based on the afore mentioned studies, the following parameters were selected for investigation: single or double cracking (number of cracks), the crack orientation relative to the reinforcing bar rib pattern, the confinement and the concrete cover.

As reinforced concrete structures are currently primarily constructed with ribbed reinforcing bars, the crack itself can cross the rib pattern of the bar at different angles. Cracks running along to the longitudinal ribs, leaving the concrete around the
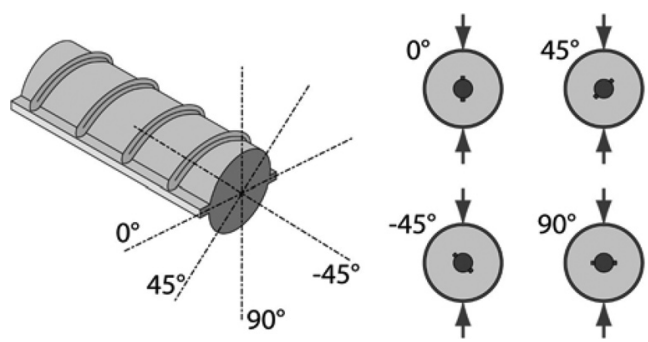

Figure 3. Applied crack orientations with respect to the reinforcing bars rib pattern.

transverse rib intact, might have a less detrimental impact on the bond compared to cracks that hit the transverse ribs. Whether this crack angle influences the bond behaviour is currently unknown.

Crack widths are often governed by the amount of transverse reinforcement. For longitudinal cracks running along the longitudinal reinforcing bars, the transverse reinforcement is providing a form of confinement transferring forces from one crack face to another and reducing the crack width. As more confinement is provided, the hoop stresses induced during pull-out of a longitudinal reinforcing bar might be counteracted and in this way provide sufficient resistance for the anchorage force to build up (Tepfers 1976).

In cases where the confinement is limited these hoop stresses might induce higher stresses in the transverse reinforcement, leading to cracks opening up and decreases in the bond properties.

Similar to the confinement provided by transverse reinforcement, the concrete cover can also provide confinement. Increasing the concrete cover leads to a bigger influence zone around the reinforcing bar that might resist the hoop stresses being built up and thereby increase the bond strength of the bar.

\subsection{Test series}

A total of 4 series of experiments are undertaken. Each series consists of 4 sets of 5 identical specimens. The entire test matrix, for the total of 80 tests carried out, is shown in Table 2.

In Series 1 the angle of a single crack with respect to the rib pattern of the bar is varied. Different angles are achieved through different orientations of the specimens relative to the applied split tensile load. In addition to a reference uncracked set, a single cracked set with crack angle of 0 degrees, 45 degrees and 90 degrees is tested. The crack angle itself is measured with respect to the plane running through the bar axis and the longitudinal ribs.

Series 2 focusses on double cracked specimens where the crack orientation relative to a reference 
Table 2. Overview of parameter combinations for the tested specimen series.

\begin{tabular}{|c|c|c|c|c|c|c|c|c|c|c|c|}
\hline \multirow[b]{2}{*}{ Series } & \multirow[b]{2}{*}{ Set } & \multicolumn{2}{|c|}{ Confinement } & \multicolumn{2}{|c|}{ Diameter $[\mathrm{mm}]$} & \multicolumn{3}{|c|}{ Single crack angle } & \multicolumn{3}{|c|}{ Double crack angle } \\
\hline & & No & Yes & 60 & 107 & 0 & 45 & 90 & $0 \& 90$ & $-45 \& 45$ & $90 \& 0$ \\
\hline \multirow[t]{4}{*}{1} & A & & $X$ & & $X$ & & & & & & \\
\hline & B & & $X$ & & $X$ & $X$ & & & & & \\
\hline & $\mathrm{C}$ & & $X$ & & $X$ & & $X$ & & & & \\
\hline & $\mathrm{D}$ & & $X$ & & $X$ & & & $X$ & & & \\
\hline \multirow[t]{4}{*}{2} & A & & $X$ & & $X$ & & & & & & \\
\hline & B & & $X$ & & $X$ & & & & $\mathrm{X}$ & & \\
\hline & $\mathrm{C}$ & & $X$ & & $X$ & & & & & $X$ & \\
\hline & $\mathrm{D}$ & & $X$ & & $X$ & & & & & & $X$ \\
\hline \multirow[t]{4}{*}{3} & A & $X$ & & & $X$ & & & & & & \\
\hline & B & $X$ & & & $X$ & $X$ & & & & & \\
\hline & $\mathrm{C}$ & $X$ & & & X & & & $\mathrm{X}$ & & & \\
\hline & $\mathrm{D}$ & $\mathrm{X}$ & & & $X$ & & & & $X$ & & \\
\hline \multirow[t]{4}{*}{4} & A & & $X$ & $X$ & & & & & & & \\
\hline & B & & $\mathrm{X}^{*}$ & $\mathrm{X}^{*}$ & $\mathrm{X}^{*}$ & $X$ & & & & & \\
\hline & $\mathrm{C}$ & & $X$ & $X$ & & $X$ & & & & & \\
\hline & $\mathrm{D}$ & & $X$ & $X$ & & & & & $X$ & & \\
\hline
\end{tabular}

* Pre-cracked specimen of $60 \mathrm{~mm}$ cast in a $107 \mathrm{~mm}$ specimen.

plane through the bar axis and longitudinal ribs varies. A reference set, a set with cracks orientated at 0 degrees and 90 degrees relative to reference plane, and a set with -45 degrees combined with 45 degrees cracks are tested. As the cracks are formed by applying a splitting test, the crack faces of the first crack are compressed during the second splitting phase. To investigate the potential influence of this sequence, a fourth set of specimens where the cracks at 90 degrees are formed first followed by cracking along the 0 degrees axis has been tested.

Series 3 consisted of specimens where the plastic tube confinement was removed after the cracking phase

In the last series, Series 4 , the concrete cover was reduced by casting the specimens in a cylindrical tube with an inner diameter of only $60 \mathrm{~mm}$, reducing the original cover by $23 \mathrm{~mm}$ and resulting in a cover-to-diameter ratio of 2.5. An uncracked reference set, a set of specimens with single crack (crack angle 0 degrees) and a set of double cracked specimens ( 0 degrees combined with 90 degrees) are tested. The final set consisted of specimens of diameter $60 \mathrm{~mm}$ single cracked at 0 degrees after which the plastic confinement was removed. The specimen was then placed in the centre of a 107 $\mathrm{mm}$ diameter plastic tube and concrete was cast in the annulus between the specimen and the tube. As a result a $23 \mathrm{~mm}$ thick concrete ring was formed around the cracked specimen. This scenario simulates a situation in which the crack starts to grow around the rebar but does not yet extend to the outer surface.
Table 3. Concrete properties.

\begin{tabular}{|c|c|c|c|c|c|}
\hline \multirow[b]{2}{*}{ Series } & \multicolumn{2}{|c|}{$\mathrm{f}_{\mathrm{c}, \text { cub }}[\mathrm{MPa}]$} & \multicolumn{2}{|c|}{$\mathrm{f}_{\mathrm{c}}[\mathrm{MPa}]$} & \multirow{2}{*}{$\frac{\mathrm{f}_{\mathrm{ct}, \mathrm{sp}}[\mathrm{MPa}]}{21 \mathrm{~d}}$} \\
\hline & $21 d$ & $28 \mathrm{~d}$ & $21 \mathrm{~d}$ & $28 \mathrm{~d}$ & \\
\hline 1 & 29.5 & 31.3 & 22.8 & 23.3 & 2.4 \\
\hline 2 & 29.0 & 30.5 & 20.0 & 20.0 & 2.6 \\
\hline 3 & 25.3 & 27.6 & 20.2 & 22.5 & 2.5 \\
\hline 4 & 28.4 & 29.0 & 23.4 & 23.8 & 2.7 \\
\hline
\end{tabular}

\subsection{Materials}

A concrete with a 28-day cube compressive strength of about $30 \mathrm{MPa}$ is selected for the tests. The waterto-cement ratio of the mixture is 0.6 and the sandto-aggregate ratio is 0.45 . The concrete is made with an early-strength Portland cement with limestone, type CEM II/A LL 32.5 R (European Committee for Standardization 2011). The aggregates are a natural sand with a maximum grain size of $4 \mathrm{~mm}$ and specific gravity of 2.65 and a gravel with maximum grain size of $10 \mathrm{~mm}$ with specific gravity of 2.65. The compressive and tensile strengths of the concrete are determined at 21 days (time of precracking) and 28 days (time of bond tests). For the determination of the compressive strength, cubes with sides of $100 \mathrm{~mm}\left(\mathrm{f}_{\mathrm{c}, \mathrm{cub}}\right)$ and cylinders with a height of $200 \mathrm{~mm}$ and a diameter of $100 \mathrm{~mm}\left(\mathrm{f}_{\mathrm{c}}\right)$ are used. The splitting tensile strength $\mathrm{f}_{\text {ct,sp }}$ is measured from cylinders with a diameter of $100 \mathrm{~mm}$ and a height of $200 \mathrm{~mm}$. The mean results for the four series are summarized in Table 3. 


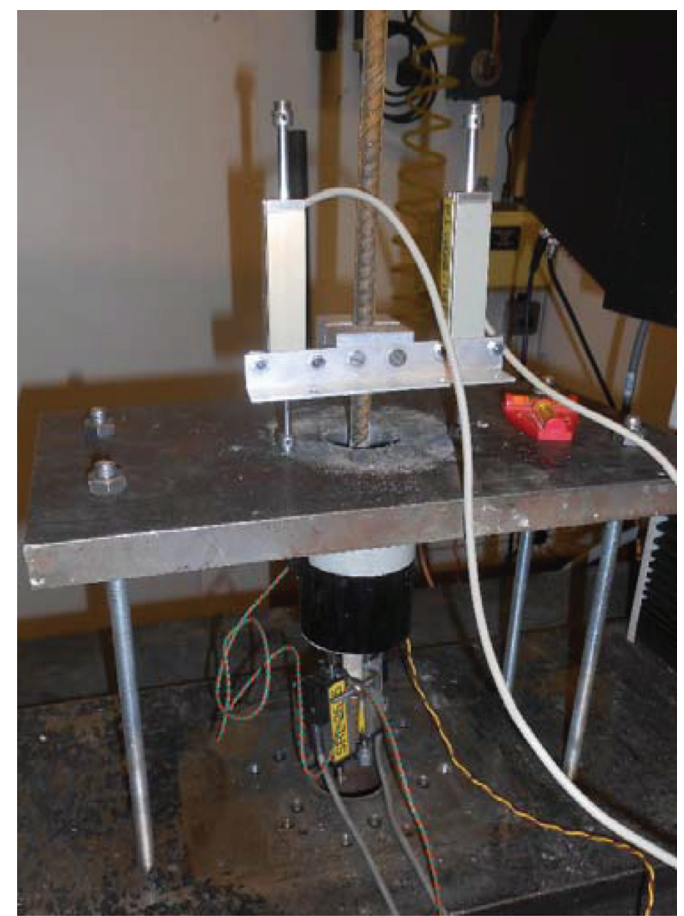

Figure 4. Instrumentation and test set-up for the pullout experiments.

The steel bar diameter is fixed for the test program at $10 \mathrm{~mm}$. The yield stress $\mathrm{f}_{\mathrm{y}}$ and tensile strength $f_{u}$ of the high-strength hot-rolled reinforcing bars, are measured in the laboratory as $520 \mathrm{MPa}$ and $606 \mathrm{MPa}$ respectively.

The confinement consisted of a plastic tube with an outer diameter of $113 \mathrm{~mm}$ with a wall thickness of $3.2 \mathrm{~mm}$ or a tube with a diameter of $64 \mathrm{~mm}$ and a wall thickness of $2.1 \mathrm{~mm}$. Both tube diameters showed a similar behaviour under tensile loads.

\subsection{Test procedure and instrumentation}

At an age of 21 days the specimens are subjected to a split cylinder test. During the splitting test, the applied force as well as the strain on the surface of the plastic tube is recorded. The tube confining strain is measured with strain gauges on opposite sides of the specimens at mid-height.

The obtained crack width is measured using a crack microscope with an accuracy of $0.01 \mathrm{~mm}$ at both sides of the reinforcement bar at a distance of $30 \mathrm{~mm}$ from the rebar in case of $107 \mathrm{~mm}$ specimens and at $20 \mathrm{~mm}$ for specimens with a diameter of $60 \mathrm{~mm}$.

The pull-out tests are performed at 28 days in a $150 \mathrm{kN}$ closed loop tensile load frame. During the

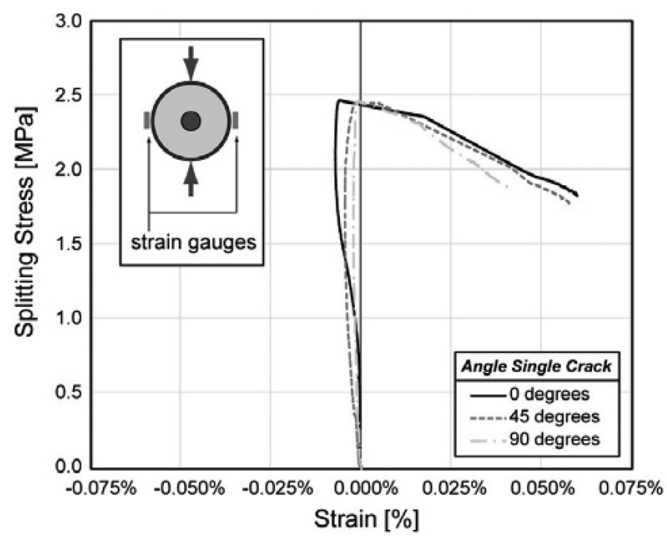

Figure 5. Confinement strains during pre-cracking tests for single cracked specimens.

pull-out tests, the specimens are loaded at a constant displacement rate of $0.04 \mathrm{~mm} / \mathrm{s}$ until a total relative displacement between the tested reinforcing bar and the surrounding concrete of at least $12.5 \mathrm{~mm}$ is reached.

The slip of the bar, at the passive as well as the active side, is recorded using 2 sets of 2 linear variable differential transducers (LVDT). These LVDT's are secured to the bar by means of a steel collar mounted to the reinforcing bar (Figure 4).

After unloading of the specimens the crack widths are measured again.

\section{RESULTS AND DISCUSSION}

\subsection{Pre-cracking of the specimens}

For the pre-cracking stage, the measured applied forces at first cracking induce splitting stresses of around $2.3 \mathrm{MPa}(\mathrm{DEV}=0.2 \mathrm{MPa})$.

Figure 5 shows one of the measured splitting stress - confinement strain responses for a Series 1 - set B, C and D specimen (single crack oriented at either 0,45 or 90 degrees relative to the longitudinal rib). The response of the other specimens was comparable. The final strain in the confinement after cracking is in the $0.04 \%$ to $0.06 \%$ range which corresponds to confinement stresses of $1.8 \mathrm{MPa}$ to 2.3 $\mathrm{MPa}$ in the plastic confinement ring.

The crack widths $\mathrm{w}$ after splitting for the precracked specimens are shown in Figure 6 for the different series and sets. The obtained values are around $0.03 \mathrm{~mm}$ but there is significant scatter. For the double cracked specimens (Series 2) the average of the two (phase 1 and phase 2) obtained crack widths is plotted. All crack patterns obtained for specimens within the same parameter combination were comparable. No anomalies were detected. 


\section{BOND STRENGTH}

From the pull-out experimental results, values of the bond stress can be derived. Assuming a uniform stress distribution along the short bond length, the force $\mathrm{F}_{\mathrm{s}}$ in the reinforcing bar is transferred to the concrete over the embedment length $l_{d}$ resulting in mean bond stresses $\tau_{\mathrm{d}}$ of:

$$
\tau_{d}=\frac{F_{s}}{l_{d} \cdot \pi \cdot \phi}=\frac{\sigma_{s}}{4 \cdot k}
$$

where $1_{d}$ can be defined as a parameter $k$ multiplied by the bar diameter $\phi(\mathrm{k} . \phi)$ and $\sigma_{\mathrm{s}}$ the tensile stress in the reinforcing bar.

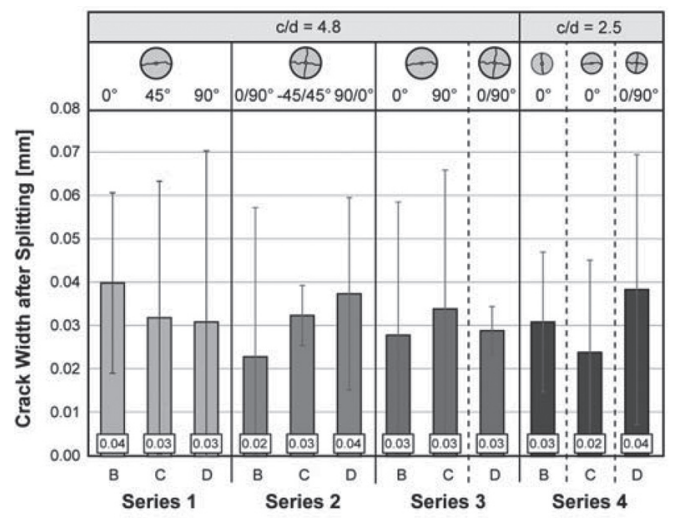

Figure 6. Crack widths $w$ after pre-cracking phase.
Two values are of particular interest: the ultimate bond strength $\tau_{\mathrm{R}}$ and the so-called characteristic bond strength $\tau_{\mathrm{M}}$. The ultimate bond strength is defined as the bond stress corresponding to the ultimate load recorded during testing. The characteristic bond strength $\tau_{\mathrm{M}}$ is calculated as the mean value of the bond stresses corresponding to a slip of $0.01 \mathrm{~mm}, 0.10 \mathrm{~mm}$ and $1.00 \mathrm{~mm}$.

The slip at the ultimate bond strength $s_{u}$ is of interest with respect to the ductility of the bond failure.

The highest ultimate bond strengths are recorded for the reference uncracked specimens, as was to be expected. The three sets of $107 \mathrm{~mm}$ diameter reference specimens $(\mathrm{c} / \mathrm{d}=4.8)$ all gave ultimate bond strengths of about 19.2 $\mathrm{MPa}(\mathrm{DEV}=1.4 \mathrm{MPa})$. The bond strength of the bars tested with a smaller cover ( $\mathrm{c} / \mathrm{d}=2.5$ for the $60 \mathrm{~mm}$ diameter specimens), turned out to be $14.3 \mathrm{MPa}(\mathrm{DEV}=0.8 \mathrm{MPa})$ as the dominant failure method in this case was splitting failure (due to the limited reinforcement cover). The ultimate bond strengths of the pre-cracked specimens were all lower than the equivalent reference specimens. The same observations can be made for the characteristic bond strength.

In the analysis hereafter the results of the bond stresses and strengths will be expressed in terms of a bond reduction factor. This factor is defined as the ratio of the actual strength of a specific set to the mean bond strength of the equivalent uncracked reference specimens in that series. In this way direct comparisons of the test results within and between series can be made.

Table 4. Experimental results of pull-out test.

\begin{tabular}{|c|c|c|c|c|c|c|c|c|c|c|}
\hline \multirow[b]{2}{*}{ Series } & \multirow[b]{2}{*}{ Set } & & \multicolumn{2}{|c|}{$\square \mathrm{R}[\mathrm{MPa}]$} & \multicolumn{2}{|c|}{$\square \mathrm{M}[\mathrm{MPa}]$} & \multicolumn{2}{|c|}{$\mathrm{Su}[\mathrm{mm}]$} & \multicolumn{2}{|c|}{$\mathrm{W}_{\mathrm{u}}[\mathrm{mm}]$} \\
\hline & & & Mean & DEV & Mean & DEV & Mean & DEV & Mean & DEV \\
\hline \multirow[t]{2}{*}{1} & $\mathrm{~A}$ & Reference & 20.2 & 1.3 & 11.0 & 0.9 & 0.95 & 0.09 & 0.00 & 0.00 \\
\hline & B & & 11.4 & 0.4 & 5.5 & 0.3 & 0.56 & 0.09 & 0.16 & 0.06 \\
\hline $\mathrm{c} / \mathrm{d}=4.8$ & $\mathrm{C}$ & Single & 11.5 & 0.5 & 6.1 & 0.3 & 0.58 & 0.11 & 0.19 & 0.06 \\
\hline Confined & $\mathrm{D}$ & & 11.1 & 0.6 & 5.6 & 0.2 & 0.57 & 0.10 & 0.18 & 0.08 \\
\hline \multirow[t]{2}{*}{2} & $\mathrm{~A}$ & Reference & 19.6 & 1.0 & 11.1 & 1.4 & 0.89 & 0.09 & 0.00 & 0.00 \\
\hline & B & & 8.7 & 0.6 & 4.0 & 0.4 & 0.65 & 0.13 & 0.08 & 0.04 \\
\hline $\mathrm{c} / \mathrm{d}=4.8$ & $\mathrm{C}$ & Double & 9.5 & 0.6 & 4.3 & 0.4 & 0.63 & 0.12 & 0.07 & 0.01 \\
\hline Confined & $\mathrm{D}$ & & 9.0 & 0.8 & 4.4 & 0.5 & 0.69 & 0.13 & 0.07 & 0.03 \\
\hline \multirow[t]{2}{*}{3} & $\mathrm{~A}$ & Reference & 17.9 & 0.9 & 10.3 & 1.0 & 0.92 & 0.14 & 0.00 & 0.00 \\
\hline & B & Single & 8.0 & 0.7 & 2.9 & 0.4 & 0.41 & 0.12 & 2.02 & 0.70 \\
\hline $\mathrm{c} / \mathrm{d}=4.8$ & $\mathrm{C}$ & & 8.1 & 1.0 & 3.4 & 1.0 & 0.54 & 0.12 & 1.62 & 0.49 \\
\hline Unconfined & D & Double & 6.4 & 1.2 & 2.3 & 0.6 & 0.38 & 0.05 & 0.89 & 0.37 \\
\hline \multirow[t]{2}{*}{4} & A & Reference & 14.3 & 0.8 & 8.2 & 1.1 & 0.45 & 0.23 & 0.12 & 0.03 \\
\hline & $\mathrm{B}^{*}$ & Single & 16.1 & 0.6 & 9.3 & 1.7 & 0.43 & 0.24 & 0.36 & 0.59 \\
\hline $\mathrm{c} / \mathrm{d}=2.5$ & C & Single & 10.6 & 0.9 & 7.1 & 1.5 & 0.31 & 0.12 & 0.13 & 0.01 \\
\hline Confined & D & Double & 8.4 & 0.9 & 4.5 & 0.6 & 0.61 & 0.20 & 0.08 & 0.02 \\
\hline
\end{tabular}

$*$ Re-cast $=$ specimen with $\mathrm{c} / \mathrm{d}=2.5$ pre-cracked and re-casted to achieve $\mathrm{c} / \mathrm{d}=4.8$ 


\subsection{Crack orientation}

The influence of the crack orientation in single cracked specimens was investigated in Series 1. Three different crack angles were considered, 0 , 45 and 90 degrees, with respect to the longitudinal ribs. The results clearly show that the obtained bond strengths are all lower than the reference bond strength. A t-test with a significance level of $95 \%$ confirmed this difference to be significant. The differences between the studied crack angles is small and statistically insignificant. Therefore it can be concluded that the orientation of the crack relative to the longitudinal rib has little to no effect on the bond strength. The presence of a single crack however results in a significant reduction in the ultimate bond strength of $44 \%$ for the tested specimens.

\subsection{Multiple cracks}

As was the case for the single cracked specimen, the orientation relative to the longitudinal rib is insignificant, as the $0-90$ degree and $-45-45$ degree double cracked specimens gave similar results. In both series the cracks led to ultimate bond strengths that are $54 \%$ lower than the uncracked specimens.

The similarity of the set 2-B and 2-D results (double crack with angles 0 and 90 degrees, and 90 and 0 degrees resp.) suggests that the order in which the cracks were formed also had little effect on the bond performance, as was to be expected from the results of the crack orientation tests. In comparison to the single cracked specimens, the double cracks tend to provide an additional reduction in bond strength of about $10 \%$.

\subsection{Confinement}

The cracked specimens tested without confinement all tended to fail due to splitting of the specimen rather than a pure pull-out failure as was the case for the other sets. As the ultimate bond strength is reached, the crack width increases drastically leading to a relatively brittle failure of the bond and hence a sudden decrease in the bond stresses with increasing slips. The larger ultimate crack widths $\mathrm{w}_{\mathrm{u}}$ associated with this behaviour are evident from the results.

The unconfined reference specimens provided similar bond strengths to equivalent confined specimens. As the bond failure for both sets was a pure pull-out failure this was to be expected. No cracks were observed on the outer surface of the concrete.

The beneficial effect of the confinement has been reported in earlier studies by (Gambarova et al. 1989) and is confirmed in this experimental program. The absence of any external confinement further reduces the bond capacity of the $10 \mathrm{~mm}$ reinforcing bars. For single cracked specimens, an additional reduction of $11 \%$ is measured whereas for the double cracked specimens this reduction is $20 \%$.

\subsection{Concrete cover}

As the concrete cover is reduced in Series 4 to a cover-to-diameter ratio of 2.5 , the failure mode of the reference specimens shifts from a pull-out failure to a splitting failure, hence a reduction in the ultimate bond strength from 19.2 to $14.2 \mathrm{MPa}$. The single cracked and double cracked specimens show a reduction relative to the reference of 25 and $41 \%$ respectively, which is slightly less than for the counterparts with a 4.8 cover-to-diameter ratio. This difference can be attributed to the changed failure mode.

For the specimens which originally have a coverto-diameter ratio of 2.5 on pre-cracking, but are recast to give a cover-to-diameter ratio of 4.8 , an increase in bond strength is measured. Compared to the original uncracked specimens, the increase is $21 \%$. The concrete ring with a thickness of $23 \mathrm{~mm}$ is sufficient to carry the hoop stresses built up during the pull-out test and hence prevent a splitting failure. Failure in these specimens occurs due to pull-out. The cracks in the inner cylinder do not extend to the surface of the uncracked concrete. Comparing these specimens to the original specimens with a cover-to-diameter ratio of 4.8 , shows that the re-cast specimens are stronger than the single cracked specimens. This suggests that the bond strength is less affected by partial cracking than in the case where the cracks extend to the other surface of the concrete. However, the bond strength is lower than measured for uncracked specimens.

\section{CONCLUSION}

Reinforcement corrosion can result in a severe form of concrete cracking. As cracks due to corrosion run along the concrete-rebar interface, the force transfer between the two materials, and more specifically the bond behaviour, is influenced.

To study the effect of the crack angle (relative to a plane running through the axis of the bar and the longitudinal ribs), extent of cracking, confinement and cover depth on the bond properties of reinforcing bars embedded in concrete, an experimental test program was conducted. Cylindrical specimens were pre-cracked by applying split tensile forces. Pull-out tests were then carried out on the cracked specimens to determine the bond properties. 


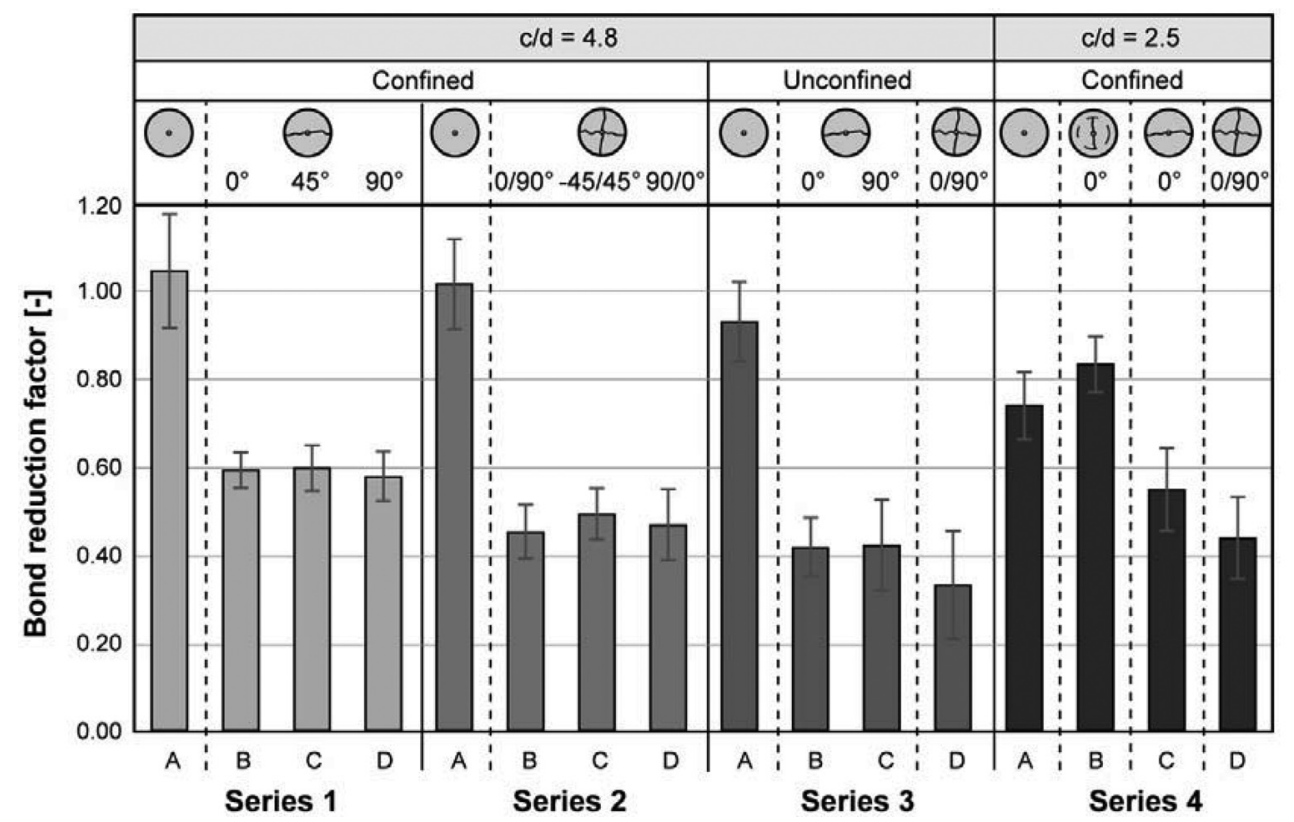

Figure 7. Bond reduction with respect to uncracked reference specimens.

The presence of cracks, even with minor crack widths of 0.03 to $0.04 \mathrm{~mm}$, result in a significant reduction of the bond strength. For specimen with a single crack the reduction was on average $44 \%$ and for double cracked specimens the reduction was $54 \%$. The measured values for single and double cracked specimens are within the relatively wide range of values reported by other researchers in the past.

The crack orientation with respect to the rib pattern of the reinforcing bars has little or no effect on the obtained bond properties. Three different crack orientations were tested and the results showed similar ultimate bond strengths.

For double cracked specimens the order in which the cracks are formed (linked to the test method) has no significant influence on the bond behaviour.

Confinement influences the ultimate bond strength of a pre-cracked specimen. In the absence of a restraining force, existing cracks can open up fully enabling the reinforcing bar to more easily slip out of the specimens. The reduction of bond capacity between confined and unconfined specimens was an additional $11 \%$ for a given parameter combination.

When the concrete cover is reduced, the residual bond strength after cracking is reduced as well. For smaller covers the failure mode of the uncracked concrete is shifted from a pull-out failure to a splitting failure.
The bond strength of reinforcing bars in cracked cylinders embedded in an uncracked concrete ring of $23 \mathrm{~mm}$ is $18 \%$ lower than the original uncracked specimens with the same total concrete cover.

The obtained test results indicate that the presence of longitudinal cracks can significantly influence the bond behaviour of ribbed reinforcing bars in concrete. This suggests that bond reduction factors are necessary for cracks that run along the reinforcement bars when undertaking load bearing capacity checks of existing reinforced concrete structures.

\section{ACKNOWLEDGEMENTS}

The authors would like to gratefully acknowledge the financial support of the UK Engineering and Physical Sciences Research Council (EPSRC) through the EPSRC Project 'Reinforced concrete half-joint structures: Structural integrity implications of reinforcement detailing and deterioration' [Grant no. EP/K016148/1].

\section{REFERENCES}

Almusallam, A. et al., 1996. Effect of reinforcement corrosion on bond strength. Construction and building Materials, 10(2), pp.123-129.

Alonso, C. et al., 1998. Factors controlling cracking of concrete affected by reinforcement corrosion. Materials and Structures, 31, pp.435-441. 
Al-Sulaimani, G., Kaleemullah, M. \& Basunbul, I., 1990. Influence of corrosion and cracking on bond behavior and strength of reinforced concrete members. $A C I$ Structural Journal, 87(2), pp.220-231.

Andrade, C., Alonso, C. \& Molina, F., 1993. Cover cracking as a function of bar corrosion: Part I-Experimental test. Materials and structures, 26, pp.453-464.

BRE Centre for Concrete Construction, 2000. Corrosion of steel in concrete-Durability of reinforced concrete structures. Digest, 444(February), p.12.

Clark, L. \& Saifullah, M., 1993. Effect of corrosion on reinforcement bond strength. In M. Forde, ed. Proceedings of the conference on structural faults \& repair. Edinbrugh, UK: Engineering Technics Press, pp. 113-119.

Clark, L. \& Saifullah, M., 1994. Effect of corrosion rate on the bond strength of corroded reinfrocement. In R. Swamy, ed. Proceedings of the international conference on corrosion and corrosion protection of steel in concrete. Sheffield, UK: Sheffield Academic Press, pp. 591-602.

European Committee for Standardization, 2011. EN 1971:2011 - Cement - Part 1: Composition, specifications and conformity criteria for common cements, Brussels, Belgium: European Committee for Standardization.
European Committee for Standardization, 2004. EN 1992-1-1 Eurocode 2: Design of concrete structuresPart 1-1: General rules and rules for buildings, European Committee for Standardization.

Gambarova, P., Rosati, G. \& Zasso, B., 1989. Steel-toconcrete bond after concrete splitting: test results. Materials and Structures, 22(1), pp.35-47.

Rilem TC, 1970. Bond test for reinforcing steel: 2. Pullout test. Materials and structures, 3(15), pp.175-178.

Rodriguez, J., Ortega, L. \& Garcia, A., 1994. Assessment of structural elements with corroded reinforcement. In R. Swamy, ed. Proceedings of the international conference on Corrosion and corrosion protection of steel in concrete. Sheffield, UK: Sheffield Academic Press, pp. 171-185.

Task Group Bond Models, 2000. fib Bulletin No. 10 Bond of Reinforcement in Concrete, Lausanne.

Tepfers, R., 1976. A theory of bond applied to overlapped tensile reinforcement splices for deformed bars 2 nd ed., Goteborg: Chalmers University of technology. 